\title{
ALK-driven tumors and targeted therapy: focus on crizotinib
}

\author{
Carlos Murga-Zamalloa \\ Megan S Lim \\ Department of Pathology, University \\ of Michigan, Ann Arbor, \\ MI, USA
}

This article was published in the following Dove Press journal:

Pharmacogenomics and Personalized Medicine

20 March 2014

Number of times this article has been viewed

\begin{abstract}
Receptor tyrosine kinases have emerged as promising therapeutic targets for a diverse set of tumors. Overactivation of the tyrosine kinase anaplastic lymphoma kinase (ALK) has been reported in several types of malignancies such as anaplastic large cell lymphoma, inflammatory myofibroblastic tumor, neuroblastoma, and non-small-cell lung carcinoma. Further characterization of the molecular role of ALK has revealed an oncogenic signaling signature that results in tumor dependence on ALK. ALK-positive tumors display a different behavior than their ALK-negative counterparts; however, the specific role of ALK in some of these tumors remains to be elucidated. Although more studies are required to establish selective targeting of ALK as a definitive therapeutic option, initial trials have shown extraordinary results in the majority of cases.
\end{abstract}

Keywords: lymphoma, therapy, kinase, pathobiology

\section{Introduction}

Cancer is a leading cause of death worldwide with an estimate of 7.6 million deaths per year and 13 million of new cases of cancer per year. The development of cancer is the result of aberrant activation of molecular signals that result from a combination of environmental insults and intrinsic cellular anomalies. ${ }^{1}$ The continuous identification of molecular targets with potential to drive oncogenesis remains a cornerstone for the designing of new selective cancer therapies.

Since the discovery of the oncogenic chromosomal translocation $t(2 ; 5)(\mathrm{p} 23 ; \mathrm{q} 25)^{2}$ and the expression of the fusion protein NPM-ALK in the majority of anaplastic large cell lymphoma (ALCL), ${ }^{3}$ several chromosomal rearrangements and mutations that lead to overactivation of anaplastic lymphoma kinase (ALK) have been identified in a variety of other human tumors. ${ }^{4}$ Genetic alterations of ALK result in the activation of a diverse set of signaling events that ultimately drive oncogenesis and render transformed cells "addicted" to ALK. The small molecule crizotinib, a selective ATP-competitive inhibitor for ALK has been evaluated in several clinical trials with initial extraordinary results, emphasizing the role of ALK in cancer. ${ }^{5}$ The following paragraphs will focus on the biological and clinical outcomes that result from overactivation of ALK, as well as the current status of its therapeutic inhibition in cancer.

\section{Oncogenic role of ALK and current therapies Anaplastic large cell lymphoma (ALCL)}

ALCL accounts for 5\% of non-Hodgkin's lymphomas and is the most common form of T cell non-Hodgkin's lymphoma in the pediatric population. ALCL was initially 
characterized as large tumor cells that resemble malignant histiocytes which were positive for the CD30 antigen. ${ }^{6}$ The translocation between chromosomes 2 and 5, which involved the $5 q 35$ locus, was originally described in a series of cases of malignant histiocytosis. ${ }^{7}$ Further analysis that includes the previous reported cases and new lymphoma cases that harbored the $\mathrm{t}(2 ; 5)(\mathrm{p} 23 ; \mathrm{q} 35)$ translocation, classified these cases as anaplastic large cell lymphoma by morphological features and CD30 expression. ${ }^{8}$ The $\mathrm{t}(2 ; 5)(\mathrm{p} 23 ; \mathrm{q} 35)$ translocation results in the fusion of the $\mathrm{N}$-terminal portion of nucleophosmin (NPM) with the C-terminal portion of ALK. ${ }^{2}$

Other partner genes for ALK translocation events have been described, including TPM3, TFG, MSN, CLTC, and ATIC. However, NPM-ALK accounts for more than $75 \%$ of the ALK+ ALCL cases reported. ${ }^{9,10}$ Expression of ALK rearrangements in ALCL ranges from $65 \%-85 \%$ and is predominant in pediatric cases. ${ }^{10}$ Different studies have shown that ALK-positive cases display better failure-free survival and overall survival rates than ALK-negative cases. ${ }^{11}$ However, these differences could be explained because the majority of ALK+ cases are predominant in the pediatric population and if adjusted by age, no significant difference in failure-free survival or overall survival is evident. ${ }^{11}$ The more important prognostic feature for ALCL is extra-nodal involvement; both ALK-positive and ALK-negative ALCL show the same frequency of extra-nodal presentation. ${ }^{11}$

One of the more characterized targets of NPM-ALK is STAT3. Activation of STAT3 by ALK results in increased transcription of genes that prevent apoptosis and promote cell cycle progression. ${ }^{12-15}$ STAT3 can also mediate silencing of genes that inhibit STAT3 signaling, ${ }^{16,17}$ generating a self-activation loop for STAT3 signaling. Perpetuation and activation of STAT3 signaling in ALCL is also enhanced by other pathways, such as JAK $3,{ }^{18}$ and autocrine effects from IL-9 ${ }^{19}$ and IL-22. ${ }^{20}$ Secretion of IL-9 or IL-22 is dependent of NPM-ALK, demonstrating kinase-independent pathways of STAT3 activation downstream of NPM-ALK.

Another important mechanism that leads to enhanced STAT3 activation is downstream of beta catenin, whose transcription is itself upregulated by NPM-ALK. Besides the enhancement of STAT3 signaling, beta catenin can also promote the transcription of genes that promote cell proliferation in ALCL. ${ }^{21}$ The signaling activity of beta catenin is perpetuated by NPM-ALK through phosphorylation of GSK3 beta, downstream of Pi3k/AKT pathways, which are directly phosphorylated by NPM-ALK. ${ }^{22}$
Besides resistance to apoptosis and increased proliferation, the oncogenic effects of NPM-ALK extend to different mechanisms, such as increased invasion and reprogramming of cellular metabolism. NPM-ALK phosphorylates PKM2 and promotes a switch in metabolism, inhibiting lactate production and promoting biomass production, which is necessary as substrate energy for proliferation. ${ }^{23}$ This effect was initially described by Warburg et al and it is recognized as one of the metabolic oncogenic pathways that favors cancer proliferation. ${ }^{24}$

Similarly, the oncogenic signature of NPM-ALK encompasses genes that are involved in actin cytoskeleton remodeling, such as paxillin. ${ }^{25}$ Phosphorylation of MMP-9 downstream of NPM-ALK promotes its activity and the degradation of extracellular matrix, promoting the invasion of transformed fibroblasts. ${ }^{26}$ Several studies have shown that NPM-ALK increases the expression of genes that are involved in actin polymerization and the migration of lymphocytes like paxillin. Direct phosphorylation of Twist-1 downstream of NPM-ALK also promotes the invasion of ALCL cell lines. ${ }^{27}$

The first intervention for ALCL patients with direct inhibition of ALK, was a report of two ALCL cases positive for ALK and refractory to chemotherapy. Both cases displayed excellent response with complete remission. ${ }^{28}$ The response for crizotinib in a clinical trial involving nine ALCL patients positive for ALK was excellent as seven patients showed complete remission, one a partial response, and one steady state tumor. ${ }^{29}$ The Children's Oncology Group has recently initiated a Phase II study of crizotinib in pediatric patients with newly diagnosed ALCL. ${ }^{30}$

\section{Inflammatory myofibroblastic tumor (IMT)}

IMT are relatively rare soft-tissue tumors that usually occur in the lung, viscera, and soft tissues; however, they can occur at any anatomical site. The majority of cases are reported in children and young adults. ${ }^{31}$ Although IMT is considered a malignant tumor, its potential for distant metastasis is very limited. Half of the cases do not show recurrence after surgical excision and recurrent tumors are usually local. IMT constitutes an oncogenic proliferation of mesenchymal cells, with a characteristic infiltration of plasma cells and lymphocytes. The tumors can show cytologic atypia; however, there is not an established relation between cellular atypia and the risk for metastasis. ${ }^{32}$

Chromosomal translocations that result in overexpression of ALK have been reported in more than $50 \%$ of $\mathrm{IMT}^{33,34}$ 
The most common translocation partners for ALK are TPM3 and TPM $4 ;^{35}$ however, other partners including DCTN1, ATIC, CLTC, CARS, RANBP2, SECT1L1, and PPFIBP1 has also been reported. ${ }^{32}$ Several studies have confirmed that ALK-positive cases occur in younger patients with no preferred anatomical location. As there is no clear histological or molecular marker that can predict the malignant transformation of IMT, several studies have compared the outcomes for IMT cases in relation to ALK expression. The results have been variable, but the risk of recurrence does not appear to be affected by the presence of ALK rearrangements. ${ }^{32}$ However, those that are positive for ALK rearrangements have a decreased risk for metastasis when compared to ALK-negative IMT. ${ }^{32}$ In contrast to other soft tissue tumors that also show positive staining for ALK, IMT are only associated with chimeric forms of ALK that do not encode the full length receptor and characteristically display high levels of ALK expression. ${ }^{36}$

Although some of the molecular pathways that underlie the oncogenic role of ALK have been characterized in ALCL, it appears that a different mechanism may be present in IMT. Increased expression of c-Myc is associated with ALK-positive ALCL ${ }^{37}$ and constitutes a bad prognostic factor; $^{38}$ in IMT, expression of c-Myc is similar between ALK-positive and ALK-negative cases. ${ }^{32}$ Similarly, Bcl-2 which is upregulated by STAT3 downstream of NPM-ALK, is detected only in a minority of cases of IMT. ${ }^{32}$

Current therapy for IMT is surgical resection, which can be coupled with chemotherapy in cases that occur with local metastases or are recurrent. One patient with local extension and refractive for chemotherapy was enrolled in a clinical trial for crizotinib. The patient showed a good response with crizotinib and remained disease-free ${ }^{39}$ In a different trial, seven patients with ALK rearrangements with IMT received crizotinib. None of the patients showed progressive disease in the time interval, three displayed partial response, and the rest remained with steady disease. ${ }^{29}$

\section{Non-small-cell lung carcinoma (NSCLC)}

Lung cancer is the leading cause of cancer death, the third most common neoplasm and represents $13 \%$ of all new cancer cases in the US. NSCLC is the predominant type and represents more than $80 \%$ of the cases. The fusion oncogene EML4-ALK was discovered in a patient with $\mathrm{NSCLC}^{40}$ and is present in a minor portion of the patients. The fusion involves the N-terminal portion of EML4 and the C-terminal portion of ALK, which encompasses the intracellular kinase domain required for kinase activity. ${ }^{40}$ The EML4-ALK fusion protein is specific for lung carcinoma and the basic N-terminal domain of EML4 is required for dimerization of the protein and successful kinase activity of ALK.

Transgenic mice that selectively express EML4-ALK in lung tissue develop multiple nodules of adenocarcinoma, and selective inhibition of ALK kinase activity has a marked effect on reduction of the tumors. ${ }^{41}$ The frequency of EML4ALK in NSCLC can be up to $7.5 \%$ and can be as high as $22 \%$ in non-smoker patients with NSCLC. ${ }^{42,43}$ The subtype of NSCLC most commonly associated with EML4-ALK is adenocarcinoma and the patients are predominantly males and young adults. ${ }^{42}$

The signaling signature of NPM-ALK has many similarities with EML4-ALK. Experiments in human fibroblasts have shown that STAT3 and ERK are also targets for the kinase activity of EML4-ALK. ${ }^{44}$ Moreover, knock-down of STAT3 or ERK is sufficient to reduce the proliferative rate and induce apoptosis in transformed fibroblasts by EML4ALK. ${ }^{44}$ However, activation of AKT/PI3 kinase pathways is not a predominant finding in EML4-ALK expressing NSCLC as has been shown for NPM-ALK expressing ALCL. ${ }^{44}$

Therapeutic inhibition of ALK using a tyrosine kinase inhibitor was evaluated for the first time in patients through a clinical trial that included 82 patients with advanced NSCLC positive for EML4-ALK. In that study, 57\% of the patients showed either partial or complete response, $33 \%$ remain at steady disease, and the disease-control rate was $87 \%$ after 8 weeks of therapy. ${ }^{45}$ The 12 -month median survival after crizotinib therapy in NSCLC was $74.8 \% .{ }^{46}$ A subsequent study comparing crizotinib versus chemotherapy in ALK-positive NSCLC showed that crizotinib had a higher response rate $(65 \%$ versus $20 \%)$ and patients reported a reduction in symptoms and overall higher quality of life with crizotinib. ${ }^{47}$ Interestingly, NSCLC patients with translocations involving ROS1 tyrosine kinase share similar clinical features to patients with EML4-ALK, and one study suggested that a subset of these patients may also benefit from crizotinib therapy. ${ }^{48}$

A small percentage of patients developed acquired resistance to crizotinib, and almost half of those cases are the result of emergent mutated ALK alleles with decreased sensitivity for crizotinib. ${ }^{49,50}$ The occurrence of acquired resistance without ALK mutations may be potentially due to the emergence of tumor clones with activation of other oncogenes such as K-ras. ${ }^{50}$ Development of a new generation of ALK inhibitors is promising for the treatment of crizotinib-resistant clones. ${ }^{51-54}$ 


\section{Neuroblastoma}

Neuroblastoma is the most common extracranial tumor in children and accounts for $12 \%$ of all cancer-related deaths in children. ${ }^{55,56}$ Neuroblastoma represents an oncogenic proliferation of neuroblast precursors and is the more severe form in the spectrum of neuroblastic tumors (including ganglioneuroblastoma and ganglioneuroma). ${ }^{57}$ Screening for ALK expression in several neuroblastoma tumors identified high-level expression of full-length ALK in a significant proportion of cases. ${ }^{58}$ Subsequently, large genetic screens identified mutations in ALK that predominantly occur in the tyrosine kinase domain and resulted in increased kinase activity. ${ }^{59-62}$ The most common change identified was the mutation of $A L K$ F1174L, although one study found R1275Q to be the predominant mutation. ${ }^{62}$ Mutated ALK at F1174L led to increased proliferation and decreased apoptosis of neuroblastoma cell lines. ${ }^{60}$

Activating mutations in $A L K$ are present in the majority of familial neuroblastoma cases and account for up $10 \%$ of sporadic cases. ${ }^{56}$ Detection of ALK by immunohistochemistry is directly proportional to the copy number of $A L K$ and somatic mutations in $A L K$ have been associated with a decrease in overall survival. ${ }^{56}$ The copy number of $A L K$ is significantly higher in neuroblastoma cases compared to the lower spectrum forms of neuroblastic tumors (GNBL and GN). ${ }^{23}$ However, no significant difference has been found for ALK expression and neuroblastoma histological grade or tumor stage. ${ }^{63}$

Amplification of the $M Y C N$ gene is the most common genetic aberration in neuroblastoma and has been associated with a bad prognosis. ${ }^{64,65}$ Both $A L K$ mutations and $M Y C N$ amplifications can occur simultaneously, predominantly with the $A L K$ F1174L change. ${ }^{66} M Y C N$ prevents sympathoadrenal differentiation from neuroblastic cells, some of which will transform into neuroblastoma, which is potentiated by overactivated ALK. ${ }^{67}$

A recent clinical trial recruited children with neuroblastoma with known or unknown $A L K$ mutations and evaluated the clinical response after treatment with crizotinib. Out of the eleven patients with known $A L K$ mutations, only one had a complete response, two remained with stable disease, and the rest showed progressive disease. Of these patients, two harbored germline mutations in $A L K$, one showed complete response, and the second stable disease. Twenty-three patients with unknown status of $A L K$ genetic alterations were enrolled; of those, only one showed complete response, five remained with stable disease, and the rest developed progressive disease. ${ }^{68}$

\section{Rhabdomyosarcoma}

Rhabdomyosarcoma is the most common soft tissue sarcoma in children. ${ }^{69}$ The prognosis for high-risk cases is poor and $50 \%$ of patients do not exceed 5 -year survival. ${ }^{70}$ Based on an initial study that screened several cell lines for ALK expression, ${ }^{71}$ a subsequent study ${ }^{36}$ evaluated ALK expression in rhabdomyosarcoma samples and other mesenchymal tumors. By immunostain detection, 19\% of rhabdomyosarcoma cases were positive for ALK. Interestingly, $40 \%$ of peripheral nerve sheet tumors, $9 \%$ of malignant fibrous histiocytomas, and $10 \%$ of leiomyosarcomas also showed positive ALK expression. A subset of cases were analyzed by FISH, and gene amplification as well as chromosomal translocations including NPM-ALK were detected..$^{36}$ Two larger studies that included $83^{72}$ and $69^{73}$ cases of rhabdomyosarcoma reported that $28 \%$ and $53 \%$ were ALK positive, respectively. One of the studies also included 16 cases of malignant mixed Müllerian tumors; out of those, $25 \%$ showed positive ALK expression. $^{72}$

Two larger studies were not able to detect ALK translocations. ${ }^{74,75}$ Instead, one of the studies detected $59 \%$ of primary tumors with gene amplifications. ${ }^{75}$ The same study showed that metastases and local recurrences displayed ALK amplifications in $72 \%$ and $78 \%$ of the cases, respectively. ${ }^{75}$ The percentage of cases with an increase in ALK copy number is variable, as a different study found those events in only $18 \%$ of the cases. ${ }^{74}$ Mutations in the coding sequence of ALK have also been detected in a subset of the cases screened $^{75}$ and the identified mutations were located in the RTK domain of ALK.

Significant association between alveolar subtype of rhabdomyosarcoma and ALK expression has been consistently observed. $^{70,72-75}$ Positive ALK expression and an increase in gene copy number show a positive relation with metastasis at time of diagnosis and worst prognosis. ${ }^{74,75}$ The large number of ALK-positive rhabdomyosarcoma cases and the elevated number of relapses with current therapies prompts ALK inhibition as a reasonable therapeutic option. ${ }^{70} \mathrm{~A}$ recent study has found that inhibition of ALK decreases the viability of rhabdomyosarcoma cell lines, especially of the alveolar subtype ${ }^{70}$ constituting a promising step toward ALK therapy for rhabdomyosarcoma.

\section{Diffuse large B-cell lymphoma (DLBCL)}

DLBCL is the most common type of lymphoid neoplasia worldwide. It affects children and adults, and may be nodal or extranodal at presentation. ${ }^{76}$ This tumor is very aggressive; however, there are reported cases with complete remission. ${ }^{76}$ 
An initial study reported a collection of seven DLBCL cases that were positive for ALK and negative for CD30 and CD20 expression. The same study showed expression of full-length ALK and no chimeric isoforms. ${ }^{77}$ Later reports described similar cases of DLBCL positive for ALK expression, which harbored chimeric isoforms of ALK, including NPM-ALK. However, the vast majority of these cases featured the $t(2 ; 17)$ (p23;q23) rearrangement that fuses clathrin (CLTC) with ALK (CLTC-ALK). ${ }^{78-84}$

Further characterization of DLBCL positive for CLTCALK translocation showed increased phosphorylation of STAT3, suggesting common molecular oncogenic mechanisms with ALK-positive ALCL. ${ }^{85}$ ALK-positive DLBCL are usually aggressive tumors that are identified at the very advanced stages. ${ }^{79,80}$ These tumors are usually not responsive to conventional chemotherapy, ${ }^{80,82,84}$ and due to the absence of CD20 expression, treatment with rituximab is not usually indicated. In vivo studies in mouse xenografts showed that B-cell lymphomas with ALK expression show a good response to ALK inhibitors. ${ }^{86,87}$ One case report of a patient with advanced stage of ALK-positive DLBCL who was refractive to chemotherapy was treated with crizotinib. The patient displayed a very short response to crizotinib, possibly due to an aberrant ALK rearrangement. ${ }^{88}$

\section{Glioblastoma}

Glioblastoma is the most common glial tumor and patients have an expected survival of 1 year, despite therapy. ${ }^{89}$ Glioblastoma is thought to develop from neural stem cells with continuous aberrant proliferation..$^{90,91}$ To further support this notion, aberrant expression of receptor tyrosine kinases involved in neural development have been detected in glioblastomas. ${ }^{71,89,92}$

After the fusion protein NPM-ALK was identified, expression of full length ALK was predominantly detected in neurons from the central and peripheral nervous system at fetal stages. ${ }^{93}$ Subsequent studies showed that pleiotrophin (PTN) was a ligand for the ALK receptor. ${ }^{94}$ PTN is a growth factor that induces tumorigenesis and is also expressed in glioblastomas. ${ }^{95}$ The PTN-ALK signaling axis promotes oncogenesis of glioblastoma ${ }^{91}$ and its inhibition abolishes tumoral growth in mice xenografts of glioblastoma cell lines. ${ }^{89,96}$ Overall, these results suggest that inhibition of ALK could be a good therapeutic target for glioblastoma.

\section{Other ALK-positive tumors}

Abnormal expression of ALK that results from either chromosome aberrancies or mutations has been reported in isolated cases from other different types of tumors, which may also benefit from ALK inhibition. ${ }^{97}$ Screening for the presence of EML4-ALK transcripts revealed that a subset of breast and colorectal cancer samples harbor this translocation. ${ }^{98}$ A subsequent study showed increased ALK signaling resulting from copy number gain or the presence of EML4-ALK in a proportion of inflammatory breast cancer samples. ${ }^{99}$ Further work has failed to identify more cases of inflammatory breast cancer positive for ALK expression, suggesting that large cohorts are required to investigate the role of ALK in this type of tumor..$^{71,100}$

Somatic mutations in ALK have been detected in two cases of anaplastic thyroid carcinoma; these mutations were located in the receptor tyrosine kinase domain and resulted in gain of function of ALK. ${ }^{101}$ Two reports have found a minor subset of melanoma cases positive for ALK expression and rearrangements. ${ }^{71,102}$ Aberrant expression of ALK has also been detected in a significant proportion of Ewing sarcoma cases and cell lines; ${ }^{103,104}$ however, no significant clinical differences have been observed between positive and negative cases. ${ }^{103}$ Mutations in the receptor tyrosine kinase domain of ALK were identified in one of these studies and crizotinib decreased the viability of ES cell lines. ${ }^{103}$

\section{Conclusion}

Aberrant activity of ALK results in the activation of signaling pathways that promote oncogenic transformation of different cell lineages. Although the role of ALK has been well established, further studies are required to understand the oncogenic mechanisms operating in ALK-positive neoplasms in order to identify different targets that may play a role in cancer biology. Selective inhibition of ALK has been proven to be an excellent option in both ALCL and NSCLC, and will need to be further evaluated in patients with other ALKpositive tumors like neuroblastoma. Studies to determine the pharmacokinetics and optimal dose of ALK inhibitors in childhood and adolescent ALCL are currently ongoing. ${ }^{30}$ Given the tumor-specific expression of $A L K$ rearrangements, other non-invasive methods for disease monitoring such as fusion-peptide detection by mass spectrometry ${ }^{105}$ or quantitative reverse-transcriptase PCR may also prove helpful in the management of patients with ALK-positive tumors. ${ }^{68}$

\section{Disclosure}

The authors report no conflicts of interest in this work.

\section{References}

1. Hanahan D, Weinberg RA. Hallmarks of cancer: the next generation Cell. 2011;144(5):646-674. 
2. Morris SW, Kirstein MN, Valentine MB, et al. Fusion of a kinase gene, ALK, to a nucleolar protein gene, NPM, in non-Hodgkin's lymphoma. Science. 1994;263(5151):1281-1284.

3. Falini B. Anaplastic large cell lymphoma: pathological, molecular and clinical features. Br J Haematol. 2001;114(4):741-760.

4. Mano H. ALKoma: a cancer subtype with a shared target. Cancer Discov. 2012;2(6):495-502.

5. Christensen JG, Zou HY, Arango ME, et al. Cytoreductive antitumor activity of PF-2341066, a novel inhibitor of anaplastic lymphoma kinase and c-Met, in experimental models of anaplastic large-cell lymphoma. Mol Cancer Thera. 2007;6(12 Pt 1):3314-3322.

6. Stein H, Mason DY, Gerdes J, et al. The expression of the Hodgkin's disease associated antigen $\mathrm{Ki}-1$ in reactive and neoplastic lymphoid tissue: evidence that Reed-Sternberg cells and histiocytic malignancies are derived from activated lymphoid cells. Blood. 1985;66(4): $848-858$.

7. Morgan R, Hecht BK, Sandberg AA, Hecht F, Smith SD. Chromosome 5 q35 breakpoint in malignant histiocytosis. $N$ Engl J Med. 1986;314(20):1322.

8. Mason DY, Bastard C, Rimokh R, et al. CD30-positive large cell lymphomas ('Ki-1 lymphoma') are associated with a chromosomal translocation involving 5q35. Br J Haematol. 1990;74(2):161-168.

9. Lowe EJ, Lim MS. Potential therapies for anaplastic lymphoma kinasedriven tumors in children: progress to date. Paediatr Drugs. 2013;15(3): 163-169.

10. Ferreri AJ, Govi S, Pileri SA, Savage KJ. Anaplastic large cell lymphoma, ALK-positive. Crit Rev Oncol Hematol. 2012;83(2):293-302.

11. Savage KJ, Harris NL, Vose JM, et al; International Peripheral T-Cell Lymphoma Project. ALK- anaplastic large-cell lymphoma is clinically and immunophenotypically different from both ALK+ ALCL and peripheral T-cell lymphoma, not otherwise specified: report from the International Peripheral T-Cell Lymphoma Project. Blood. 2008;111(12):5496-5504.

12. Zamo A, Chiarle R, Piva R, et al. Anaplastic lymphoma kinase (ALK) activates Stat3 and protects hematopoietic cells from cell death. Oncogene. 2002;21(7):1038-1047.

13. Zhang Q, Raghunath PN, Xue L, et al. Multilevel dysregulation of STAT3 activation in anaplastic lymphoma kinase-positive T/null-cell lymphoma. J Immunol. 2002;168(1):466-474.

14. Amin HM, McDonnell TJ, Ma Y, et al. Selective inhibition of STAT3 induces apoptosis and $\mathrm{G}(1)$ cell cycle arrest in ALK-positive anaplastic large cell lymphoma. Oncogene. 2004;23(32):5426-5434.

15. Chiarle R, Simmons WJ, Cai H, et al. Stat3 is required for ALKmediated lymphomagenesis and provides a possible therapeutic target. Nat Med. 2005;11(6):623-629.

16. Khoury JD, Rassidakis GZ, Medeiros LJ, Amin HM, Lai R. Methylation of SHP1 gene and loss of SHP1 protein expression are frequent in systemic anaplastic large cell lymphoma. Blood. 2004;104(5): $1580-1581$.

17. Zhang Q, Wang HY, Marzec M, Raghunath PN, Nagasawa T, Wasik MA. STAT3- and DNA methyltransferase 1-mediated epigenetic silencing of SHP-1 tyrosine phosphatase tumor suppressor gene in malignant T lymphocytes. Proc Natl Acad Sci U S A. 2005;102(19):6948-6953.

18. Amin HM, Medeiros LJ, Ma Y, et al. Inhibition of JAK3 induces apoptosis and decreases anaplastic lymphoma kinase activity in anaplastic large cell lymphoma. Oncogene. 2003;22(35):5399-5407.

19. Qiu L, Lai R, Lin Q, et al. Autocrine release of interleukin-9 promotes Jak3-dependent survival of ALK+ anaplastic large-cell lymphoma cells. Blood. 2006;108(7):2407-2415.

20. Bard JD, Gelebart P, Anand M, Amin HM, Lai R. Aberrant expression of IL-22 receptor 1 and autocrine IL-22 stimulation contribute to tumorigenicity in ALK+ anaplastic large cell lymphoma. Leukemia. 2008;22(8):1595-1603.

21. Anand M, Lai R, Gelebart P. $\beta$-catenin is constitutively active and increases STAT3 expression/activation in anaplastic lymphoma kinasepositive anaplastic large cell lymphoma. Haematologica. 2011;96(2): $253-261$.
22. McDonnell SR, Hwang SR, Basrur V, et al. NPM-ALK signals through glycogen synthase kinase $3 \beta$ to promote oncogenesis. Oncogene. 2012;31(32):3733-3740.

23. McDonnell SR, Hwang SR, Rolland D, et al. Integrated phosphoproteomic and metabolomic profiling reveals NPM-ALK-mediated phosphorylation of PKM2 and metabolic reprogramming in anaplastic large cell lymphoma. Blood. 2013;122(6):958-968.

24. Warburg O, Wind F, Negelein E. The metabolism of tumors in the body. J Gen Physiol. 1927;8(6):519-530.

25. Lim MS, Carlson ML, Crockett DK, et al. The proteomic signature of NPM/ALK reveals deregulation of multiple cellular pathways. Blood. 2009;114(8):1585-1595.

26. Lagarrigue F, Dupuis-Coronas S, Ramel D, et al. Matrix metalloproteinase-9 is upregulated in nucleophosmin-anaplastic lymphoma kinase-positive anaplastic lymphomas and activated at the cell surface by the chaperone heat shock protein 90 to promote cell invasion. Cancer Res. 2010;70(17):6978-6987.

27. Zhang J, Wang P, Wu F, et al. Aberrant expression of the transcriptional factor Twist1 promotes invasiveness in ALK-positive anaplastic large cell lymphoma. Cell Signal. 2012;24(4):852-858.

28. Gambacorti-Passerini C, Messa C, Pogliani EM. Crizotinib in anaplastic large-cell lymphoma. N Engl J Med. 2011;364(8):775-776.

29. Mossé YP, Balis FM, Lim MS, et al. Efficacy of crizotinib in children with relapsed/refractory ALK-driven tumors including anaplastic large cell lymphoma and neuroblastoma: a Children's Oncology Group phase I consortium study. J Clin Oncol. 2012; 30(Suppl; abstr 9500).

30. National Cancer Institute (NCI). Brentuximab vedotin or crizotinib and combination chemotherapy in treating patients with newly diagnosed stage II-IV anaplastic large cell lymphoma. Available from: http://clinicaltrials.gov/ct2/show/NCT01979536. NLM identifier: NCT01979536. Accessed February 7, 2014.

31. Coffin CM, Watterson J, Priest JR, Dehner LP. Extrapulmonary inflammatory myofibroblastic tumor (inflammatory pseudotumor). A clinicopathologic and immunohistochemical study of 84 cases. Am J Surg Pathol. 1995;19(8):859-872.

32. Coffin CM, Hornick JL, Fletcher CD. Inflammatory myofibroblastic tumor: comparison of clinicopathologic, histologic, and immunohistochemical features including ALK expression in atypical and aggressive cases. Am J Surg Pathol. 2007;31(4):509-520.

33. Griffin CA, Hawkins AL, Dvorak C, Henkle C, Ellingham T, Perlman EJ. Recurrent involvement of 2p23 in inflammatory myofibroblastic tumors. Cancer Res. 1999;59(12):2776-2780.

34. Chan JK, Cheuk W, Shimizu M. Anaplastic lymphoma kinase expression in inflammatory pseudotumors. Am J Surg Pathol. 2001;25(6): 761-768.

35. Lawrence B, Perez-Atayde A, Hibbard MK, et al. TPM3-ALK and TPM4-ALK oncogenes in inflammatory myofibroblastic tumors. Am J Pathol. 2000;157(2):377-384.

36. Cessna MH, Zhou H, Sanger WG, et al. Expression of ALK1 and p80 in inflammatory myofibroblastic tumor and its mesenchymal mimics: a study of 135 cases. Mod Pathol. 2002;15(9):931-938.

37. RaetzEA, Perkins SL, Carlson MA, Schooler KP, Carroll WL, Virshup DM. The nucleophosmin-anaplastic lymphoma kinase fusion protein induces c-Myc expression in pediatric anaplastic large cell lymphomas. Am J Pathol. 2002;161(3):875-883

38. Moritake H, Shimonodan H, Marutsuka K, Kamimura S, Kojima H, Nunoi H. C-MYC rearrangement may induce an aggressive phenotype in anaplastic lymphoma kinase positive anaplastic large cell lymphoma: Identification of a novel fusion gene ALO17/C-MYC. Am J Hematol. 2011;86(1):75-78.

39. Butrynski JE, D'Adamo DR, Hornick JL, et al. Crizotinib in ALKrearranged inflammatory myofibroblastic tumor. $N$ Engl $J$ Med. 2010;363(18):1727-1733.

40. Soda M, Choi YL, Enomoto M, et al. Identification of the transforming EML4-ALK fusion gene in non-small-cell lung cancer. Nature. 2007;448(7153):561-566. 
41. Soda M, Takada S, Takeuchi K, et al. A mouse model for EML4ALK-positive lung cancer. Proc Nat Acad Sci U S A. 2008;105(50): 19893-19897.

42. Shaw AT, Yeap BY, Mino-Kenudson M, et al. Clinical features and outcome of patients with non-small-cell lung cancer who harbor EML4ALK. J Clin Oncol. 2009;27(26):4247-4253.

43. Kim HR, Shim HS, Chung JH, et al. Distinct clinical features and outcomes in never-smokers with nonsmall cell lung cancer who harbor EGFR or KRAS mutations or ALK rearrangement. Cancer. 2012;118(3):729-739.

44. Takezawa K, Okamoto I, Nishio K, Janne PA, Nakagawa K. Role of ERK-BIM and STAT3-survivin signaling pathways in ALK inhibitorinduced apoptosis in EML4-ALK-positive lung cancer. Clin Cancer Res. 2011;17(8):2140-2148.

45. Kwak EL, Bang YJ, Camidge DR, et al. Anaplastic lymphoma kinase inhibition in non-small-cell lung cancer. N Engl J Med. 2010;363(18): 1693-1703.

46. Camidge DR, Bang YJ, Kwak EL, et al. Activity and safety of crizotinib in patients with ALK-positive non-small-cell lung cancer: updated results from a phase 1 study. Lancet Oncol. 2012;13(10):1011-1019.

47. Shaw AT, Kim DW, Nakagawa K, et al. Crizotinib versus chemotherapy in advanced ALK-positive lung cancer. $N$ Engl J Med. 2013;368(25): 2385-2394.

48. Bergethon K, Shaw AT, Ou SH, et al. ROS1 rearrangements define a unique molecular class of lung cancers. J Clin Oncol. 2012;30(8): $863-870$

49. Choi YL, Soda M, Yamashita Y, et al. EML4-ALK mutations in lung cancer that confer resistance to ALK inhibitors. $N$ Engl J Med. 2010;363(18):1734-1739.

50. Doebele RC, Pilling AB, Aisner DL, et al. Mechanisms of resistance to crizotinib in patients with ALK gene rearranged non-small cell lung cancer. Clin Cancer Res. 2012;18(5):1472-1482.

51. Mori M, Ueno Y, Konagai S, et al. The selective anaplastic lymphoma receptor tyrosine kinase inhibitor ASP3026 induces tumor regression and prolongs survival in non-small cell lung cancer model mice. Mol Cancer Thera. Epub January 27, 2014.

52. Marsilje TH, Pei W, Chen B, et al. Synthesis, structure-activity relationships, and in vivo efficacy of the novel potent and selective anaplastic lymphoma kinase (ALK) inhibitor 5-chloro-N2-(2-isopropoxy5-methyl-4-(piperidin-4-yl)phenyl)-N4-(2-(isopropylsulfonyl)phenyl) pyrimidine-2,4-diamine (LDK378) currently in phase 1 and phase 2 clinical trials. J Med Chem. 2013;56(14):5675-5690.

53. Katayama R, Khan TM, Benes C, et al. Therapeutic strategies to overcome crizotinib resistance in non-small cell lung cancers harboring the fusion oncogene EML4-ALK. Proc Nat Acad Sci U SA. 2011;108(18): 7535-7540.

54. Seto T, Kiura K, Nishio M, et al. CH5424802 (RO5424802) for patients with ALK-rearranged advanced non-small-cell lung cancer (AF-001JP study): a single-arm, open-label, phase 1-2 study. Lancet Oncol. 2013;14(7):590-598.

55. Schulte JH, Schulte S, Heukamp LC, et al. Targeted therapy for neuroblastoma: ALK inhibitors. Klin Padiatr. 2013;225(6):303-308.

56. Pugh TJ, Morozova O, Attiyeh EF, et al. The genetic landscape of high-risk neuroblastoma. Nature genetics. 2013;45(3):279-284

57. Janoueix-Lerosey I, Schleiermacher G, Delattre O. Molecular pathogenesis of peripheral neuroblastic tumors. Oncogene. 2010;29(11): 1566-1579.

58. Lamant L, Pulford K, Bischof D, et al. Expression of the ALK tyrosine kinase gene in neuroblastoma. Am J Pathol. 2000;156(5):1711-1721.

59. Chen Y, Takita J, Choi YL, et al. Oncogenic mutations of ALK kinase in neuroblastoma. Nature. 2008;455(7215):971-974.

60. George RE, Sanda T, Hanna M, et al. Activating mutations in ALK provide a therapeutic target in neuroblastoma. Nature. 2008;455(7215) 975-978.

61. Janoueix-Lerosey I, Lequin D, Brugieres L, et al. Somatic and germline activating mutations of the ALK kinase receptor in neuroblastoma. Nature. 2008;455(7215):967-970.
62. Mosse YP, Laudenslager M, Longo L, et al. Identification of ALK as a major familial neuroblastoma predisposition gene. Nature. 2008;455(7215):930-935.

63. Wang M, Zhou C, Sun Q, et al. ALK amplification and protein expression predict inferior prognosis in neuroblastomas. Exp Mol Pathol. 2013;95(2):124-130.

64. Brodeur GM, Seeger RC, Schwab M, Varmus HE, Bishop JM. Amplification of N-myc in untreated human neuroblastomas correlates with advanced disease stage. Science. 1984;224(4653):1121-1124.

65. Seeger RC, Brodeur GM, Sather H, et al. Association of multiple copies of the N-myc oncogene with rapid progression of neuroblastomas. N Engl J Med. 1985;313(18):1111-1116.

66. De Brouwer S, De Preter K, Kumps C, et al. Meta-analysis of neuroblastomas reveals a skewed ALK mutation spectrum in tumors with MYCN amplification. Clin Cancer Res. 2010;16(17):4353-4362.

67. Zhu S, Lee JS, Guo F, et al. Activated ALK collaborates with MYCN in neuroblastoma pathogenesis. Cancer Cell. 2012;21(3):362-373.

68. Mossé YP, Lim MS, Voss SD, et al. Safety and activity of crizotinib for paediatric patients with refractory solid tumours or anaplastic large-cell lymphoma: a Children's Oncology Group phase 1 consortium study. Lancet Oncol. 2013;14(6):472-480.

69. Ognjanovic S, Linabery AM, Charbonneau B, Ross JA. Trends in childhood rhabdomyosarcoma incidence and survival in the United States, 1975-2005. Cancer. 2009;115(18):4218-4226.

70. van Gaal JC, Roeffen MH, Flucke UE, et al. Simultaneous targeting of insulin-like growth factor-1 receptor and anaplastic lymphoma kinase in embryonal and alveolar rhabdomyosarcoma: a rational choice. Eur J Cancer. 2013;49(16):3462-3470.

71. Dirks WG, Fahnrich S, Lis Y, Becker E, MacLeod RA, Drexler HG. Expression and functional analysis of the anaplastic lymphoma kinase (ALK) gene in tumor cell lines. Int J Cancer. 2002;100(1):49-56.

72. Pillay K, Govender D, Chetty R. ALK protein expression in rhabdomyosarcomas. Histopathology. 2002;41(5):461-467.

73. Corao DA, Biegel JA, Coffin CM, et al. ALK expression in rhabdomyosarcomas: correlation with histologic subtype and fusion status. Pediatr Dev Pathol. 2009;12(4):275-283.

74. Yoshida A, Shibata T, Wakai S, et al. Anaplastic lymphoma kinase status in rhabdomyosarcomas. Mod Pathol. 2013;26(6):772-781.

75. van Gaal JC, Flucke UE, Roeffen MH, et al. Anaplastic lymphoma kinase aberrations in rhabdomyosarcoma: clinical and prognostic implications. J Clin Oncol. 2012;30(3):308-315.

76. Kjeldsberg CR. Practical Diagnosis of Hematologic Disorders. Chicago, IL: American Society of Clinical Pathology (ASCP); 2010;2.

77. Delsol G, Lamant L, Mariame B, et al. A new subtype of large B-cell lymphoma expressing the ALK kinase and lacking the 2; 5 translocation. Blood. 1997;89(5):1483-1490.

78. Bubala H, Maldyk J, Wlodarska I, Sonta-Jakimczyk D, Szczepanski T. ALK-positive diffuse large B-cell lymphoma. Pediatr Blood Cancer. 2006;46(5):649-653.

79. Beltran B, Castillo J, Salas R, et al. ALK-positive diffuse large B-cell lymphoma: report of four cases and review of the literature. J Hematol Oncol. 2009;2:11.

80. Chikatsu N, Kojima H, Suzukawa K, et al. ALK+, CD30-, CD20- large B-cell lymphoma containing anaplastic lymphoma kinase (ALK) fused to clathrin heavy chain gene (CLTC). Mod Pathol. 2003;16(8):828-832.

81. De Paepe P, Baens M, van Krieken H, et al. ALK activation by the CLTC-ALK fusion is a recurrent event in large B-cell lymphoma. Blood. 2003;102(7):2638-2641.

82. Gascoyne RD, Lamant L, Martin-Subero JI, et al. ALK-positive diffuse large B-cell lymphoma is associated with Clathrin-ALK rearrangements: report of 6 cases. Blood. 2003;102(7):2568-2573.

83. Gesk S, Gascoyne RD, Schnitzer B, et al. ALK-positive diffuse large B-cell lymphoma with ALK-Clathrin fusion belongs to the spectrum of pediatric lymphomas. Leukemia. 2005;19(10):1839-1840.

84. Onciu M, Behm FG, Downing JR, et al. ALK-positive plasmablastic B-cell lymphoma with expression of the NPM-ALK fusion transcript: report of 2 cases. Blood. 2003;102(7):2642-2644. 
85. Momose S, Tamaru J, Kishi H, et al. Hyperactivated STAT3 in ALK-positive diffuse large B-cell lymphoma with clathrin-ALK fusion. Hum Pathol. 2009;40(1):75-82.

86. Van Roosbroeck K, Cools J, Dierickx D, et al. ALK-positive large B-cell lymphomas with cryptic SEC31A-ALK and NPM1-ALK fusions. Haematologica. 2010;95(3):509-513.

87. Cerchietti L, Damm-Welk C, Vater I, et al. Inhibition of anaplastic lymphoma kinase (ALK) activity provides a therapeutic approach for CLTC-ALK-positive human diffuse large B cell lymphomas. PloS one. 2011;6(4):e18436.

88. Wass M, Behlendorf T, Schadlich B, et al. Crizotinib in refractory ALKpositive diffuse large B-cell lymphoma: a case report with a short-term response. Eur J Haematol. Epub December 14, 2013.

89. Powers C, Aigner A, Stoica GE, McDonnell K, Wellstein A. Pleiotrophin signaling through anaplastic lymphoma kinase is rate-limiting for glioblastoma growth. J Biol Chem. 2002;277(16):14153-14158.

90. Holland EC, Celestino J, Dai C, Schaefer L, Sawaya RE, Fuller GN. Combined activation of Ras and Akt in neural progenitors induces glioblastoma formation in mice. Nat Genet. 2000;25(1):55-57.

91. Koyama-Nasu R, Haruta R, Nasu-Nishimura Y, et al. The pleiotrophinALK axis is required for tumorigenicity of glioblastoma stem cells. Oncogene. Epub May 20, 2013.

92. Nister M, Claesson-Welsh L, Eriksson A, Heldin CH, Westermark B. Differential expression of platelet-derived growth factor receptors in human malignant glioma cell lines. J Biol Chem. 1991;266(25): 16755-16763

93. Iwahara T, Fujimoto J, Wen D, et al. Molecular characterization of ALK, a receptor tyrosine kinase expressed specifically in the nervous system. Oncogene. 1997;14(4):439-449.

94. Stoica GE, Kuo A, Aigner A, et al. Identification of anaplastic lymphoma kinase as a receptor for the growth factor pleiotrophin. J Biol Chem. 2001;276(20):16772-16779.

95. Mentlein R, Held-Feindt J. Pleiotrophin, an angiogenic and mitogenic growth factor, is expressed in human gliomas. J Neurochem. 2002;83(4): $747-753$.
96. Stylianou DC, Auf der Maur A, Kodack DP, et al. Effect of single-chain antibody targeting of the ligand-binding domain in the anaplastic lymphoma kinase receptor. Oncogene. 2009;28(37): 3296-3306.

97. Hallberg B, Palmer RH. Mechanistic insight into ALK receptor tyrosine kinase in human cancer biology. Nat Rev Cancer. 2013;13(10): 685-700.

98. Lin E, Li L, Guan Y, et al. Exon array profiling detects EML4-ALK fusion in breast, colorectal, and non-small cell lung cancers. Mol Cancer Res. 2009;7(9):1466-1476.

99. Robertson FM, Petricoin Iii EF, Van Laere SJ, et al. Presence of anaplastic lymphoma kinase in inflammatory breast cancer. SpringerPlus. 2013;2:497.

100. Krishnamurthy S, Woodward W, Yang W, et al. Status of the anaplastic lymphoma kinase (ALK) gene in inflammatory breast carcinoma. SpringerPlus. 2013;2:409.

101. Murugan AK, Xing M. Anaplastic thyroid cancers harbor novel oncogenic mutations of the ALK gene. Cancer Res. 2011;71(13): 4403-4411.

102. Niu HT, Zhou QM, Wang F, et al. Identification of anaplastic lymphoma kinase break points and oncogenic mutation profiles in acral $/$ mucosal melanomas. Pigment Cell Melanoma Res. 2013;26(5):646-653.

103. Fleuren ED, Roeffen MH, Leenders WP, et al. Expression and clinical relevance of MET and ALK in Ewing sarcomas. Int J Cancer. 2013;133(2):427-436.

104. Li XQ, Hisaoka M, Shi DR, Zhu XZ, Hashimoto H. Expression of anaplastic lymphoma kinase in soft tissue tumors: an immunohistochemical and molecular study of 249 cases. Hum Pathol. 2004;35(6):711-721.

105. Conlon KP, Basrur V, Rolland D, et al. Fusion peptides from oncogenic chimeric proteins as putative specific biomarkers of cancer. Mol Cell Proteomics. 2013;12(10):2714-2723.
Pharmacogenomics and Personalized Medicine

\section{Publish your work in this journal}

Pharmacogenomics and Personalized Medicine is an international, peerreviewed, open access journal characterizing the influence of genotype on pharmacology leading to the development of personalized treatment programs and individualized drug selection for improved safety, efficacy and sustainability. This journal is indexed on the American Chemical

\section{Dovepress}

Society's Chemical Abstracts Service (CAS). The manuscript management system is completely online and includes a very quick and fair peer-review system, which is all easy to use. Visit http://www.dovepress. com/testimonials.php to read real quotes from published authors. 